\title{
CORRESPONDENCE
}

\section{IRIDENCLEISIS IN CONGESTIVE GLAUCOMA}

\section{To The Editorial Committee of the British Journal of Ophthalmology}

SiRS-It is always gratifying to find oneself on the side of the angels, for which reason I much appreciated the paper by Mackie and Rubinstein (1954). In doing what they advocate I have hitherto felt some secret self-contempt for choosing a line of so little resistance, performing so simple an operation rather than face the hazards of the classical iridectomy.

May I suggest a modification of the ab externo approach which I find advantageous. With "Conjunctival-fold Fixation Forceps" (Stenhouse Stewart, 1934), a fold of conjunctiva is held at the limbus and an incision made through conjunctiva and sclera with a BP No. 15 blade close to the jaws of the forceps. After the iris has been dealt with, the forceps are released, the conjunctiva springs back, and no suturing is necessary. This should obviate the theoretical disadvantage of scarring beneath a dissected conjunctival flap mentioned by these authors. An advantage is that one can operate without an assistant, as the forceps can be turned down to rest on the drape after the incision is made, thus freeing both hands for attention to the iris.

I am always surprised that Stenhouse Stewart's excellent instrument is not more widely known and used. I find it admirable for a variety of purposes.

$$
\text { I am, etc., }
$$

\section{A. J. BOASF.}

Box 43. Kampala, Uganda.

December 24, 1954.

\section{REFERENCES}

MACKIE, E. G., and Rubinstein, K. (1954). British Journal of Ophthalmology, 38, 641. Stenhouse STEWART, D. (1934). Ibid., 18, 274.

\section{BOOK REVIEWS}

Text-Book of Ophthalmology, Volume VII, Summary of Systemic Ophthalmology. General Index. By Sir Stewart Duke-Elder. 1954. Pp. $245+$ vii. Kimpton, London. (25s.).

Sir Stewart Duke-Elder has incorporated in this new volume a number of up-to-date therapeutic notes because, as he points out, Volume II was written before the discovery of sulphonamides, and since the appearance of Volume III penicillin and other antibiotics, together with cortisone and kindred substances, have revolutionized the treatment of many diseases. 